\title{
Awareness of Recent Advances in Dental Extraction Techniques Among Interns
}

\author{
Sohaib Shahzan ${ }^{1}$ and Madhulaxmi M² \\ ${ }^{1}$ Saveetha Dental College and Hospitals Saveetha University of Medical and \\ Technical Science(SIMATS) Saveetha University, Chennai, India \\ ${ }^{2}$ Professor, Department of Oral and Maxillofacial Surgery, Saveetha Dental College and hospitals, Saveetha \\ University of Medical And Technical Science(SIMATS), Saveetha University, Chennai, India
}

\section{ABSTRACT}

The aim of this study was to assess the awareness on recent advances in dental extraction techniques among interns. There have been several exciting technological advances in dental extraction techniques within the last decade. There have been several exciting technological advances in extraction techniques and outpatient oral surgery within the last decade. A variety of new instruments and techniques are revolutionizing the fields of oral and maxillofacial surgery and dentistry. A set of questionnaire was framed and an online survey was conducted among inteerns using survey planet. 100 people have taken the survey and the results were statistically analyzed. In this study 59\% of students are not aware of recent advances in dental extraction techniques.61\% students are aware of physics forceps, sonosurgery and benex technique.58\%, 59\%, 57\% students are not aware about piezo surgery, luxator periotomes and EASY X-TRAC system respectively. 95\% students found this survey helpful to gain knowledge about recent advances. Hence, the study draws attention that the students are not aware about recent advances of extraction. We need to create more awareness by seminars, CD programs and hands on lectures on recent advances in dental extraction techniques.

KEY WORDS: RECENT ADVANCES, EXTRACTION, PHYSICS FORCEPS, PIEZO SURGERY, SONO SURGERY, BENEX TECHNIQUE, LUXATOR PERIOTOMES.

\section{INTRODUCTION}

Dental extraction is removal of a tooth from the mouth. It is the most common procedure performed in oral surgery, and it is often the first surgical procedure carried out by interns and dental residents(Cicciù et al., 2013; El-Kenawy and Ahmed, 2015; Senthil Kumar et al., 2019).An ideal

\section{ARTICLE INFORMATION}

*Corresponding Author: madhulaxmi@saveetha.com Received 10th June 2020 Accepted after revision 5th August 2020 Print ISSN: 0974-6455 Online ISSN: 2321-4007 CODEN: BBRCBA

Thomson Reuters ISI Web of Science Clarivate Analytics USA and Crossref Indexed Journal

\section{Clarivate
Analytics}

NAAS Journal Score 2020 (4.31) SJIF: 2020 (7.728)

A Society of Science and Nature Publication,

Bhopal India 2020. All rights reserved.

Online Contents Available at: http//www.bbrc.in/

Doi: http://dx.doi.org/10.21786/bbrc/13.7/61 tooth extraction may be defined as painless removal of the full tooth or tooth roots with minimal trauma to the investing tissues, therefore the wound heals uneventfully with no postoperative prosthetic problems(Howe, 1962; El-Kenawy and Ahmed, 2015; Wahab et al., 2018). However tooth extraction is a traumatic procedure that results in immediate destruction and loss of surrounding alveolar bone and soft tissue(Caplanis, Lozada and Kan, 2005; Patel et al., 2016). The sequence of extraction by conventional methods involves stripping of the periodontium around the tooth followed by luxation with an elevator or forceps(Feck, 2010; Jain et al., 2017).

This method invites inadvertent trauma to the surrounding hard and soft tissues and may aggravate if forceps extraction fails and surgical removal is performed, the

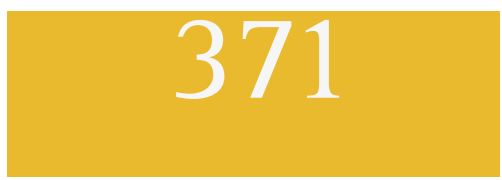


amount of soft tissue and bone loss increases, which may lead to unfavorable postoperative sequel, thereby comprising the harmony (Misch and Perez, 2008; Jain et al., 2017). Immediately after tooth removal, bony walls of the extraction socket undergo remodelling by simultaneous resorption and deposition, which leads to reduction in the bone height by 1 to $2 \mathrm{~mm}$ in all dimensions (Patil, Rakhewar and Doiphode, 2012; Jain et al., 2017). Once the wound is left to heal, considering ignorance and economy of rehabilitation, atrophy occurs as the socket is not replaced with a suitable prosthetic component(Jain et al., 2017).This disuse atrophy causes further loss in bone width by a quarter.(Jain et al., 2017).

There are several exciting technological advances in extraction techniques in oral surgery within the last decade(Weiss, Stern and Dym, 2011). A variety of new techniques and instruments are revolutionizing the fields of oral and maxillofacial surgery and dentistry(White, Holtzclaw and Toscano, 2009; Weiss, Stern and Dym, 2011). Atraumatic dental extraction techniques have gained prominence and may ultimately become the standard technique for teeth removal(Saund and Dietrich, 2013; El-Kenawy and Ahmed, 2015). Atraumatic extraction technique helps in preserving the bone, gingival structure, and allows for the choice of future or immediate implant placement(Dym and Weiss, 2012; El-Kenawy and Ahmed, 2015). A number of tools and techniques have been proposed for minimally invasive tooth removal such as physics forceps, powertome, proximators, periotomes and benex extractor(Kosinski, 2012; El-Kenawy and Ahmed, 2015).

With a rich case bank established over 3 decades we have been able to publish extensively in our domain((Abdul Wahab et al., 2017; Eapen, Baig and Avinash, 2017; Patil et al., 2017; Jain and Nazar, 2018; J et al., 2018; Marimuthu et al., 2018; Wahab et al., 2018; Abhinav et al., 2019; Ramadorai, Ravi and Narayanan, 2019; Senthil Kumar et al., 2019; Sweta, Abhinav and Ramesh, 2019). Based on this inspiration we aimed to assess the awareness on recent advances in dental extraction techniques among interns. In this study we asked the students about atraumatic extraction techniques like physics forceps, sonosurgery, piezosurgery,luxator periotomes,Benex technique and EASY X-TRAC system to assess the awareness on recent advances in dental extraction techniques among interns.

\section{MATERIAL AND METHODS}

This is a questionnaire-based study. A questionnaire was prepared with questions pertaining to recent advances in dental extraction techniques. The survey was conducted among interns .The participants volunteered for the survey.The questionnaire was administered through a survey planet link to all the participants. 100 students have participated in the survey. There were 15 questions posed to assess the awareness of recent advances in dental extraction including the knowledge about physics forceps, sonosurgery, Benex technique, vertical pulling technique, piezosurgery, EASY X-TRAC, luxator, periotomes and their mechanical advantages.

\section{RESULT AND DISCUSSION}

In this study 59\% of students are not aware of recent advances in dental extraction techniques. We found that $61 \%$ students are aware of physics forceps and advantages of it.The Physics Forceps uses first-class level mechanics to atraumatically extract a tooth from its socket(Golden, 2005; Weiss, Stern and Dym, 2011). One handle of the device is connected to a "bumper," which acts as a fulcrum during the extraction(Golden, 2005; Weiss, Stern and Dym, 2011)(15,10). This bumper is usually placed on the facial aspect of the dental alveolus, typically at the mucogingival junction(Misch and Perez, 2008; Weiss, Stern and Dym, 2011).
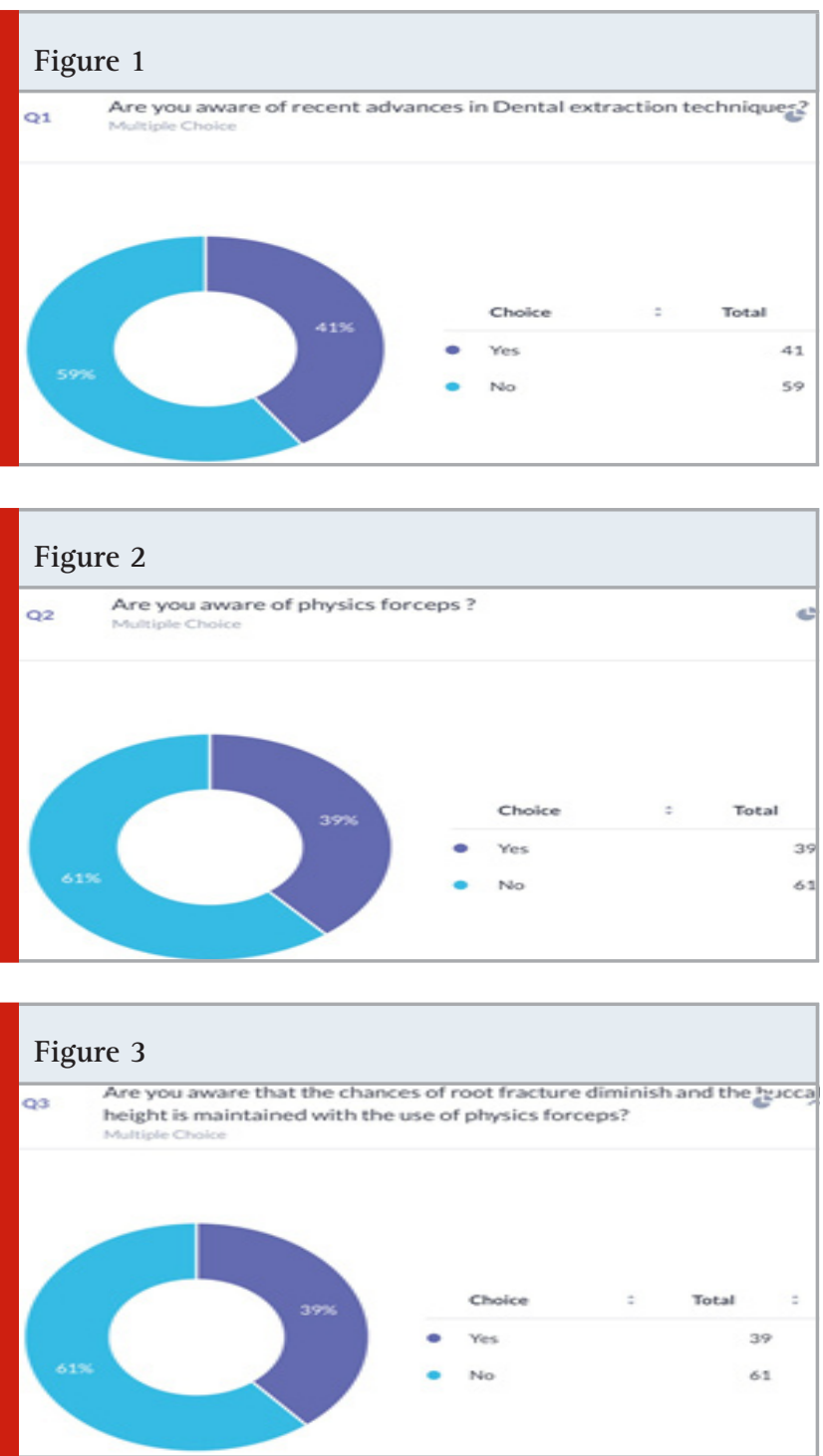

The beak of the extractor is positioned most often on the lingual or palatal root of the tooth and into the gingival sulcus(Misch and Perez, 2008; Weiss, Stern and Dym, 2011).Unlike conventional forceps, only one point of contact is made on the tooth being extracted. Together 
the "beak and bumper" design acts as a simple first-class lever. A squeezing motion should not used with these forceps. By contrast, the handles are actually rotated as one unit using a steady yet gentle rotational force with wrist movement only(Weiss, Stern and Dym, 2011).The chances of root fracture diminish and the buccal height is maintained with the use of physics forceps(Patel et al., 2016). An immediate implant placement can be considered after using physics forceps(Weiss, Stern and Dym, 2011).

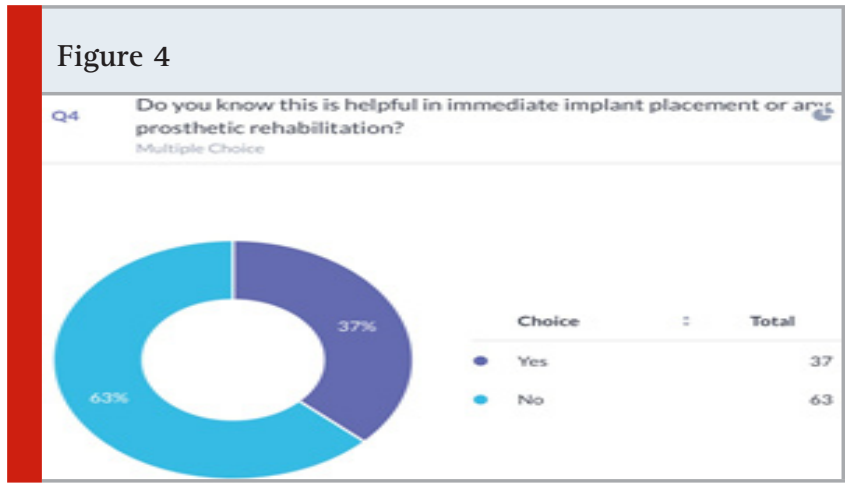

Figure 5

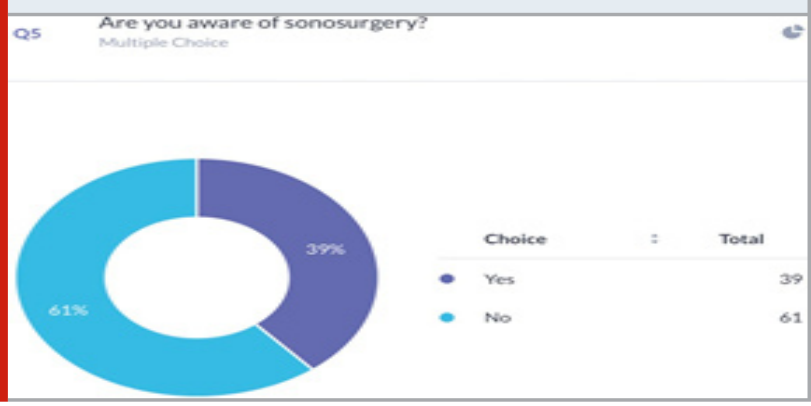

Figure 6

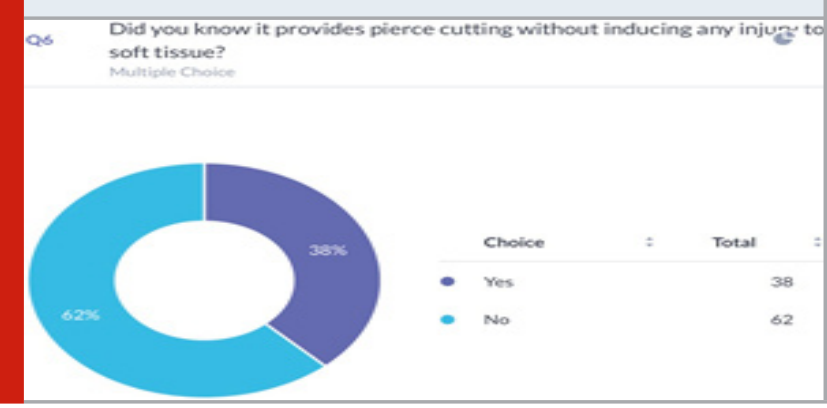

Figure 7

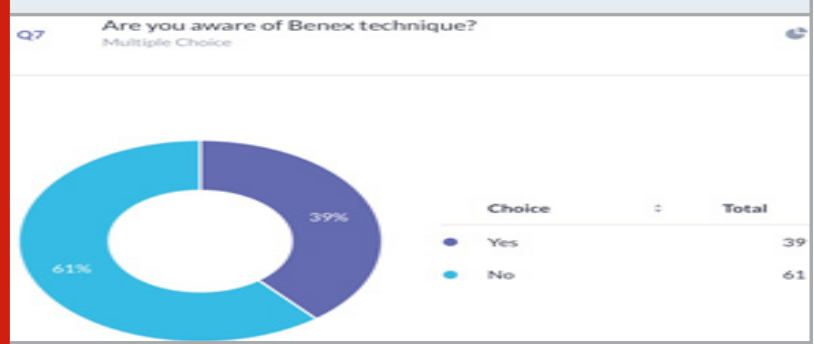

61\% students are not aware of sonosurgery .It provides precise cutting without inducing any injury to the soft tissue(Papadimitriou et al., 2012). Advantages include reduced operative time, average heat generated is less. Smooth cutting surface with minimal damage to adjacent structures provides better tactile perception and makes it safer for adjacent hard and soft tissues(Weiss, Stern and Dym, 2011; Papadimitriou et al., 2012). Disadvantages are long working time. If the direction of instrument while insertion is wrong, it may fracture while oscillating. Sonic instruments are contraindicated in patients with pacemaker as the oscillations might interfere with their functioning. In addition to this, it is not advised to use sonic instruments in patients with infectious diseases as the aerosols may further aggravate the condition(Weiss, Stern and Dym, 2011; Papadimitriou et al., 2012).

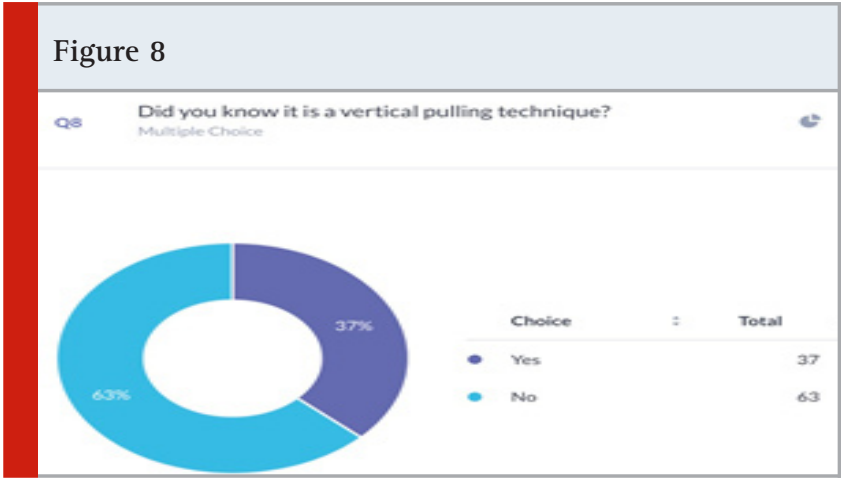

Figure 9

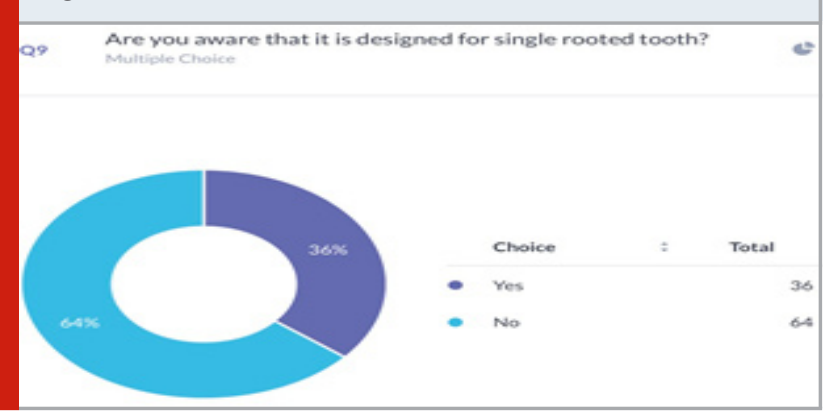

Figure 10

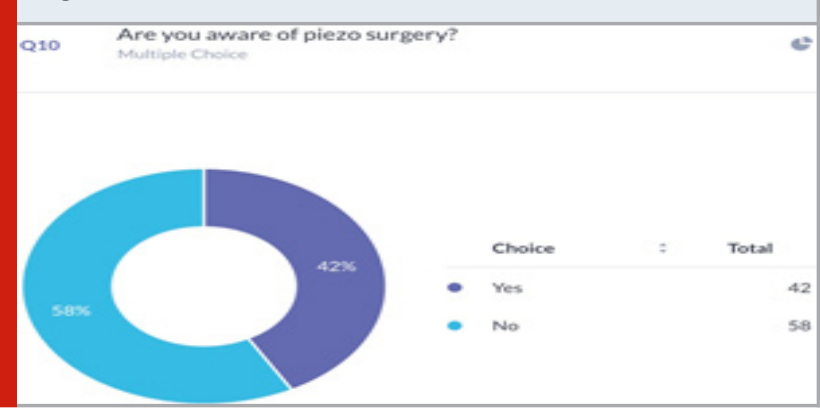

$61 \%$ students are not aware of benex technique.It works on the principle of vertical pulling only(Saund and Dietrich, 2013). This technique is specifically designed for single-rooted tooth below the marginal gingiva. The apparatus comprises a Benex extractor, diamond 
drill (1.6, $1.8 \mathrm{~mm})$, self-tapping screws, a pullstring, and a sectional impression tray(Muska et al., 2013). The disadvantages of this technique are that it cannot be used in the cases where there is inappropriate root morphology and in grossly carious teeth where retention of screw is not possible(Jain et al., 2017).
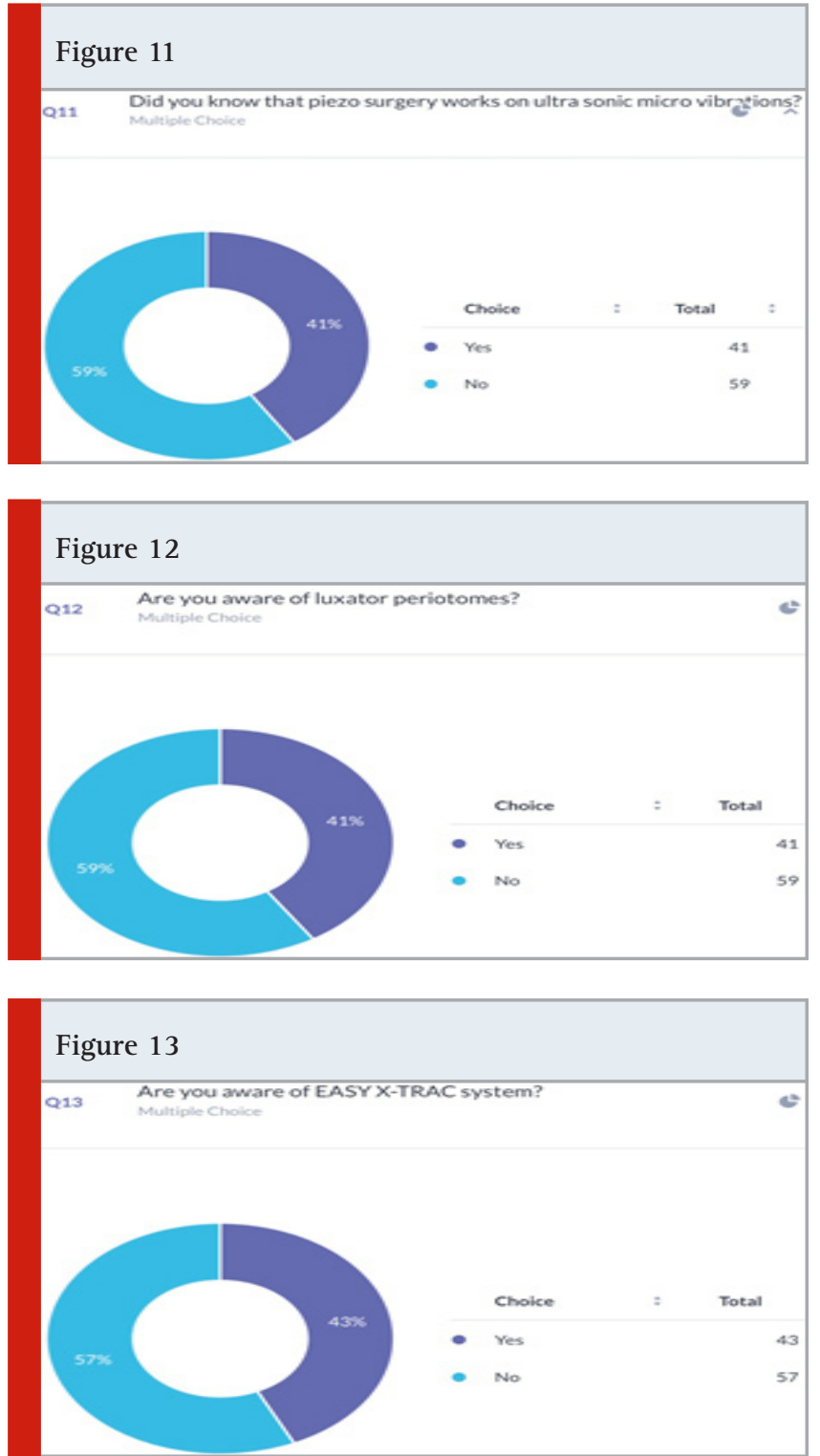

$58 \%$ students are not aware of piezo surgery.It is a procedure for hard tissue surgery, sparing the soft tissue surrounding it(Jain et al., 2017). The working principle is based on the ultrasonic micro vibrations. Performing dental extractions with piezoelectric instruments aids in faster healing as the damage to surrounding soft tissue is significantly reduced and it also leads to reduced postoperative pain.The advantages of this technique include reduced bleeding, thereby, providing a clearer surgical field and causing insignificant damage to adjacent soft tissues including lingual nerve, inferior alveolar nerve, and Schneiderian membrane. Disadvantages during its use are increased heat generation and increased surgical time along with high cost of its armamentarium.(Pavlíková et al., 2011). $59 \%$ students are not aware of luxator periotomes. These sharp slender instruments are inserted between the tooth and the gingiva trying to engage them in a plane that strips the periodontal fibers through slight, yet firm, rotatory motion. While stripping these fibers when a rocking motion is given continuously, the socket also expands. The amount of force applied during its use is significantly less.(Jones, 2012).

57\% students are not aware about EASY X-TRAC system respectively.Easy X-Trac engages into the tooth root through a screw, which aids in better retention and control. With equal distribution of forces, both the screw and root can be removed. Three color-coded drills in increasing diameter are available with two X-Trac screws of sizes 28 and $33 \mathrm{~mm}$ respectively, along with protective plates to disperse the pressure equally on both sides and a ratchet wrench to engage the screw. This technique can be used for single- and double-rooted tooth, which are ankylosed or fractured (Jain et al., 2017). 95\% students found this survey helpful to gain knowledge about recent advances.

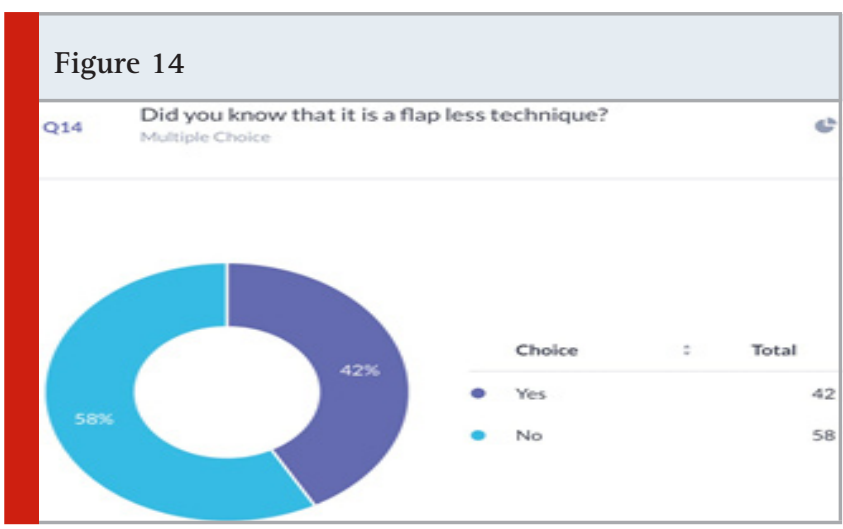

Figure 15

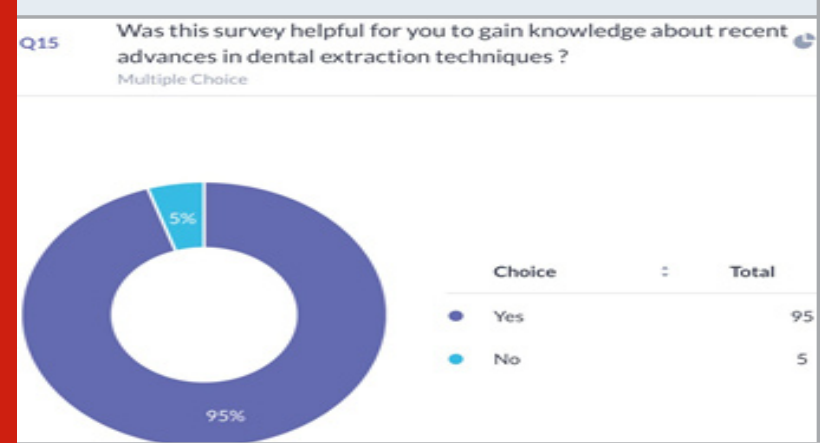

\section{CONCLUSION}

According to this survey, students are not aware about the recent advances in dental extraction techniques. The conventional forceps extraction is being followed traditionally. Whether it is the lack of practical exposure, unavailability of access to the equipments due to cost or other factors need to be further explored. Devising newer equipments to ease an existing procedure fails to meet 
the purpose when unknown and unused. More awareness has to be created by conducting seminars, CDE programs and by giving hands on lectures about recent advances in dental extraction techniques.

\section{ACKNOWLEDGEMENTS}

The authors would like to acknowledge all the participants who took up the survey

Conflict of Interest: There are no conflicts of interests to declare.

\section{REFERENCES}

Abdul Wahab, P. U. et al. (2017) 'Risk Factors for Postoperative Infection Following Single Piece Osteotomy', Journal of maxillofacial and oral surgery, 16(3), pp. 328-332.

Abhinav, R. P. et al. (2019) 'The Patterns and Etiology of Maxillofacial Trauma in South India', Annals of maxillofacial surgery, 9(1), pp. 114-117.

Caplanis, N., Lozada, J. L. and Kan, J. Y. K. (2005) 'Extraction defect assessment, classification, and management', Journal - California Dental Association, 33(11), pp. 853-863.

Cicciù, M. et al. (2013) 'Experimental study on strength evaluation applied for teeth extraction: an in vivo study', The open dentistry journal. Bentham Science Publishers, 7, p. 20.

Dym, H. and Weiss, A. (2012) 'Exodontia: tips and techniques for better outcomes', Dental clinics of North America, 56(1), pp. 245-66, x.

Eapen, B. V., Baig, M. F. and Avinash, S. (2017) 'An Assessment of the Incidence of Prolonged Postoperative Bleeding After Dental Extraction Among Patients on Uninterrupted Low Dose Aspirin Therapy and to Evaluate the Need to Stop Such Medication Prior to Dental Extractions', Journal of maxillofacial and oral surgery, 16(1), pp. 48-52.

El-Kenawy, M. H. and Ahmed, W. M. S. (2015) 'Comparison Between Physics and Conventional Forceps in Simple Dental Extraction', Journal of maxillofacial and oral surgery, 14(4), pp. 949-955.

Feck, A. (2010) 'Predictable atraumatic dental extractions', Dent Econ. http://www. dentaleconomics. com. Available at: https://www.physicsforceps.com/pdf/ dental_economics_oct_2010.pdf.

Golden, R. (2005) '... pliers design with offsetting jaw and pad elements for assisting in removing upper and lower teeth and method for removing teeth utilizing the dental plier design', US Patent App. 11/095,355. Available at: https://patents.google.com/patent/ US20050170314A1/en.

Howe, G. L. (1962) 'Some complications of tooth extraction', Annals of the Royal College of Surgeons of England, 30, pp. 309-323.

Jain, M. and Nazar, N. (2018) 'Comparative Evaluation of the Efficacy of Intraligamentary and Supraperiosteal Injections in the Extraction of Maxillary Teeth: A Randomized Controlled Clinical Trial', The journal of contemporary dental practice, 19(9), pp. 1117-1121.

Jain, S. et al. (2017) 'Advances in Methods of Atraumatic Tooth Removal: An Update', International Journal of Preventive and Clinical Dental Research, pp. 295-299. doi: 10.5005/jp-journals-10052-0129.

Jones, S. (2012) 'Atraumatic extractions with Luxator Periotome', Dental Tribune Daily US. pdfs. semanticscholar.org, 4(6), pp. 7-8.

J, P. C. et al. (2018) 'Prevalence and measurement of anterior loop of the mandibular canal using CBCT: A cross sectional study', Clinical implant dentistry and related research, 20(4), pp. 531-534.

Kosinski, T. (2012) 'Use of innovative physics forceps for extraction in preparation for dental implants', Implant News Views, 14(2), pp. 1-9.

Marimuthu, M. et al. (2018) 'Canonical Wnt pathway gene expression and their clinical correlation in oral squamous cell carcinoma', Indian journal of dental research: official publication of Indian Society for Dental Research, 29(3), pp. 291-297.

Misch, C. and Perez, H. (2008) 'Atraumatic extractions: a biomechanical route', Dentistry today, 27(8).

Muska, E. et al. (2013) 'Atraumatic vertical tooth extraction: a proof of principle clinical study of a novel system', Oral surgery, oral medicine, oral pathology and oral radiology, 116(5), pp. e303-10.

Papadimitriou, D. E. V. et al. (2012) 'Sonosurgery for atraumatic tooth extraction: a clinical report', The Journal of prosthetic dentistry, 108(6), pp. 339-343.

Patel, H. S. et al. (2016) 'Comparative Evaluation of Efficacy of Physics Forceps versus Conventional Forceps in Orthodontic Extractions: A Prospective Randomized Split Mouth Study', Journal of clinical and diagnostic research: JCDR, 10(7), pp. ZC41-5.

Patil, S. B. et al. (2017) 'Comparison of Extended Nasolabial Flap Versus Buccal Fat Pad Graft in the Surgical Management of Oral Submucous Fibrosis: A Prospective Pilot Study', Journal of maxillofacial and oral surgery, 16(3), pp. 312-321.

Patil, S. S., Rakhewar, P. S. and Doiphode, S. S. (2012) 'Strategic extraction: An unexampled epitome altering our profession', Journal of Dental Implants. Medknow Publications and Media Pvt. Ltd., 2(2), p. 121.

Pavlíková, G. et al. (2011) 'Piezosurgery in oral and maxillofacial surgery', International journal of oral and maxillofacial surgery, 40(5), pp. 451-457.

Ramadorai, A., Ravi, P. and Narayanan, V. (2019) 'Rhinocerebral Mucormycosis: A Prospective Analysis 
of an Effective Treatment Protocol', Annals of maxillofacial surgery, 9(1), pp. 192-196.

Saund, D. and Dietrich, T. (2013) 'Minimally-invasive tooth extraction: doorknobs and strings revisited!', Dental update, 40(4), pp. 325-6, 328-30.

Senthil Kumar, M. S. et al. (2019) 'Inflammatory pseudotumour of the maxillary sinus: clinicopathological report', Oral Surgery, 12(3), pp. 255-259.

Sweta, V. R., Abhinav, R. P. and Ramesh, A. (2019) 'Role of Virtual Reality in Pain Perception of Patients Following the Administration of Local Anesthesia', Annals of maxillofacial surgery, 9(1), pp. 110-113.
Wahab, P. U. A. et al. (2018) 'Scalpel Versus Diathermy in Wound Healing After Mucosal Incisions: A SplitMouth Study', Journal of oral and maxillofacial surgery: official journal of the American Association of Oral and Maxillofacial Surgeons, 76(6), pp. 1160-1164.

Weiss, A., Stern, A. and Dym, H. (2011) 'Technological advances in extraction techniques and outpatient oral surgery', Dental clinics of North America, 55(3), pp. 501-13, viii.

White, J., Holtzclaw, D. and Toscano, N. (2009) 'Powertome assisted atraumatic tooth extraction', J Implant Adv Clin Dent, 1(6), pp. 35-44. 